\title{
Early cretaceous absolute geomagnetic paleointensities from Córdoba Province (Argentina)
}

\author{
Ruben Cejudo Ruiz ${ }^{1}$, Avto Goguitchaichvilii ${ }^{1,2 *}$, Silvana E. Geuna ${ }^{3}$, Luis M. Alva-Valdivia ${ }^{1}$, Jesus Solé ${ }^{4}$, and Juan Morales ${ }^{1}$ \\ ${ }^{1}$ Laboratorio de Paleomagnetismo, Instituto de Geofiïca, UNAM, Ciudad Universitaria s/n, 04510 Mexico D.F. \\ ${ }^{2}$ Laboratorio Interinstitucional de Magnetismo Natural, Instituto de Geofisica, UNAM, Coeneo, Michoacán. \\ ${ }^{3}$ Laboratorio 'Daniel Valencio', Departamento de Ciencias Geologicas, Facultad de Cs. Exactas y Naturales, \\ Pab. 2(1428), Buenos Aires, Argentina. \\ ${ }^{4}$ Instituto de Geologia, UNAM, Ciudad Universitaria s/n, 04510 Mexico, D.F.
}

(Received December 6, 2005; Revised March 31, 2006; Accepted April 7, 2006; Online published November 8, 2006)

\begin{abstract}
We present here new paleointensity and geochronology results from Early Cretaceous volcanic rocks of Sierra Chica de Cordoba (Argentina). The new K-Ar isotopic ages of 5 samples range from 136 to 122 Ma. Twenty five samples from 7 individual flows yielded acceptable paleointensity estimates. The mean paleointensity values per flow are ranging from $53.0 \pm 1.9$ to $25.4 \pm 2.6 \mu \mathrm{T}$ and the corresponding Virtual Dipole Moments (VDMs) are ranging from $9.3 \pm 1.3$ to $4.6 \pm 0.5\left(10^{22} \mathrm{Am}^{2}\right)$. This corresponds to the mean value of $7.3 \pm 1.7 \times 10^{22} \mathrm{Am}^{2}$, which is compatible to the present geomagnetic axial dipole. Currently available selected paleointensity data from 80 to 130 Ma suggest that geomagnetic field strength frequently fluctuated before and during the Cretaceous Normal Superchron while the magnetic polarity maintained stable. The mean paleointensities derived from Córdoba lavas agree remarkably well with those obtained from the Paraná Magmatic Province (133-132 Ma). This reinforces the hypothesis about the unreliability of 'Mesozoic Dipole Low'.
\end{abstract}

Key words: Paleointensity, rock-magnetism, Early Cretaceous, South America.

\section{Introduction}

Considering the magnetic polarity time scale for the last $160 \mathrm{My}$, it is observed that the majority of polarity intervals lies in the time range of 0.1 to $1 \mathrm{My}$, while the CNS (Cretaceous Normal Superchron) is a clear outlier with a duration of about $35 \mathrm{Ma}$ from 118 to $83 \mathrm{Ma}$ (Cande and Kent, 1995). Thus CNS cannot be accommodated in the rest of the polarity sequence. This observation suggests that the geodynamo must have two fundamental states: a reversing state and a non-reversing state (McFadden and Merrill, 1995). Larson and Olson (1991) found that the magnetic field will cease to change polarity if the amplitude of convection in the outer core rises above some limit, and they speculated that the CNS (i.e. the non-reversing state of the geodynamo) corresponds to a period with strong convection in the Earth's outer core. They also predicted an abnormally high paleointensity of the geomagnetic field during the CNS. Hence, reliable paleointensity estimate from the CNS are important in order to both constrain geodynamo theory and provide a mean for better understand the long term evolution of the geodynamo. Another important point concern the precursor of CNS. Mcfadden and Merril (2000) suggested a long-term thermal influence of mantle convection on core dynamics accompanied by the gradual decreases of the re-

\footnotetext{
*At sabbatical Departamento de Geologia y Mineralogía, Universidad Michoacana San Nicolas de Hidalgo.

Copyright (c) The Society of Geomagnetism and Earth, Planetary and Space Sciences (SGEPSS); The Seismological Society of Japan; The Volcanological Society of Japan; The Geodetic Society of Japan; The Japanese Society for Planetary Sciences; TERRAPUB.
}

versal rate between 160 and $120 \mathrm{Ma}$. On the other hand, Hulot and Galet (2003) propose a mechanism of a sudden non-linear transition between a reversing and non-reversing state of the terrestrial dynamo.

Absolute paleointensity determinations before and during CNS are still scarce and of variable qualities. In this study, we report new paleointensity data from Cordoba province (Argentina) which have several advantages: (1) they are widely distributed in a large volcanic province and easy to access; (2) they record faithfully the magnetic field that existed at the time of their eruption (Geuna and Vizan, 1998); (3) Most of them are fresh for isotopic dating and have already yielded reliable K-Ar ages.

\section{Rudiments of Sierra Chica de Córdoba Geol- ogy, Sampling and Ages Determination}

Sierra Chica de Córdoba is a north-trending, westwardverging, fault-bounded basement uplift in Central Argentina (Fig. 1). The basement is uncomformably covered by Cretaceous sedimentary, volcano-sedimentary and volcanic rocks, which represent remnants of a continental basin that possibly covered the whole Sierra Chica area, and which was eroded following a Neogene reactivation episode (Andean compression). The Cretaceous rocks were included by Gordillo and Lencinas (1967) in the Sierra de Los Cóndores Group, composed of coarse red beds intercalated with basalt-andesite flows. Volcanic rocks are potassiumrich, moderately alkaline basalts and subordinate andesites. Deuteric alteration is intense, affecting mainly olivine, and has been attributed by Gordillo and Lencinas (1967) to cooling in an oxidizing environment. 


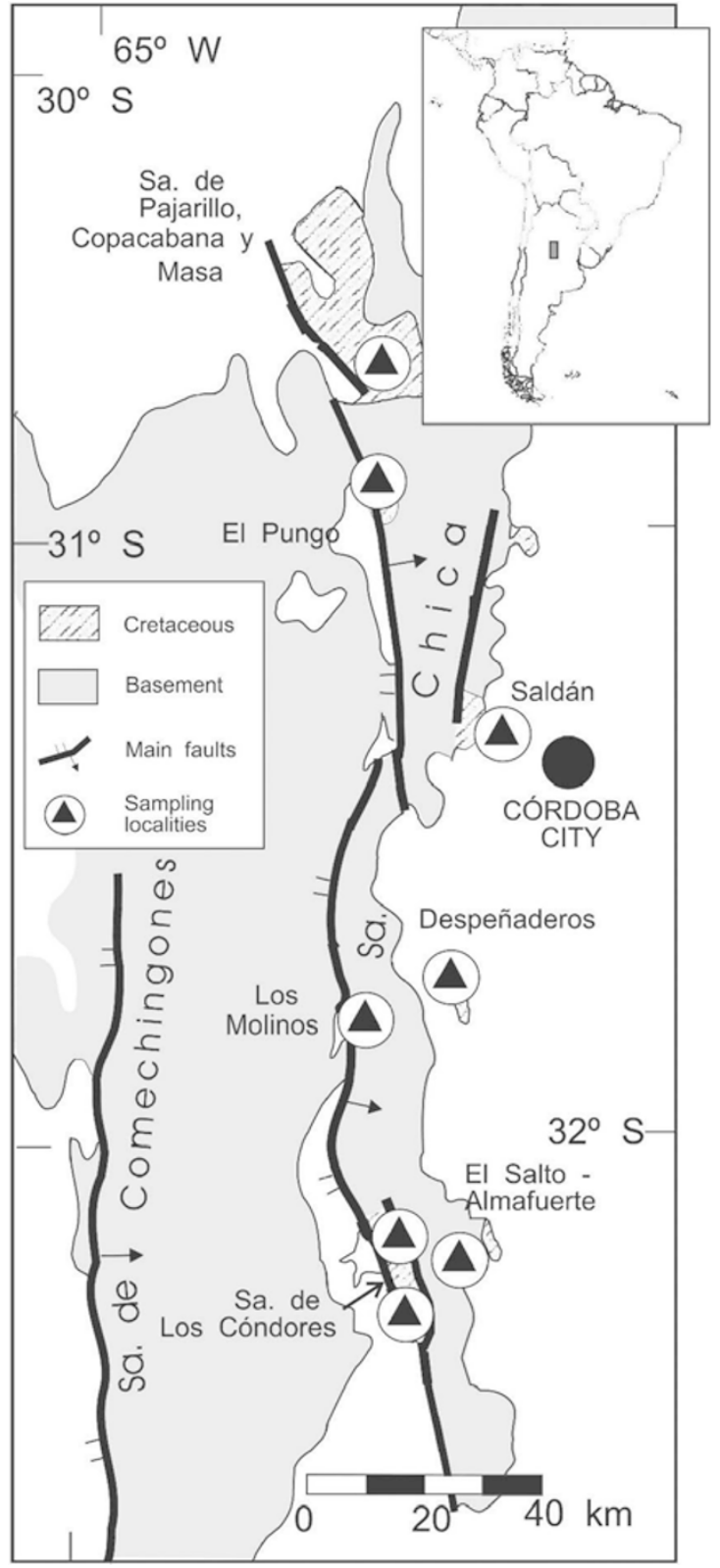

Fig. 1. Schematic map of the Sierra Chica de Córdoba showing Early Cretaceous outcrops and sampling localities (adapted from Geuna and Vizan, 1998).

As part of their efforts to study the paleotectonic evolution of the region, Geuna and Vizan (1998) carried out a systematic paleomagnetic survey in the area. 147 Sites belonging to seven localities were studied in detail. The samples were distributed throughout each flow both horizontally and vertically in order to minimize effects of block tilting and lightning. From their large collection we selected two localities (El Salto Almafuerte and Despeñaderos) with the suitable rock-magnetic and directional behavior for paleointensity determination. Special effort was done for the Despeñaderos locality (Fig. 1), which presents 12 reddishbrown consecutive basaltic lava flows yielding stable remanent magnetization (Geuna and Vizan, 1998).

The ages for the Sierra Chica de Córdoba volcanics range from 133 to $115 \mathrm{Ma}$ (Linares and González, 1990) according to the available radiometric data (Fig. 2). However, no

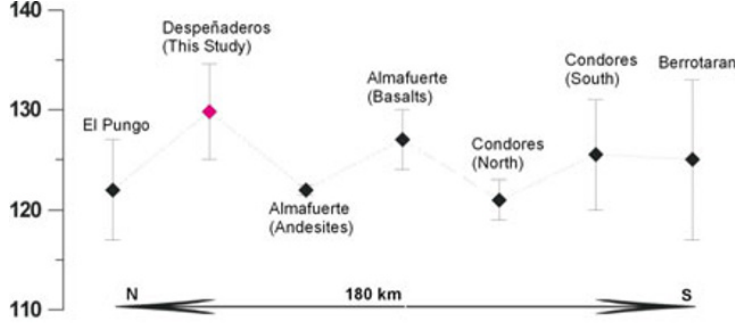

Fig. 2. Available K-Ar ages for the Sierra Chica de Córdoba volcanic formations. The new determinations are also incorporated.

radiometric data are available for the Despeñaderos locality. Thus, a special attention was given to obtain more $\mathrm{K}$ Ar absolute ages. The crushed whole rock samples were sieved at 400-500 $\mu \mathrm{m}$ and both the least magnetic fraction and most magnetic were eliminated using a Frantz magnetic separator. The resultant fractions, considered the most representative of each sample (roughly equivalent to groundmass), were cleaned, dried and split in two parts, one for $\mathrm{K}$ determination and other for Ar measurement. For sample Despeñaderos 1-2, the most altered one, we separated also the magnetic fraction for analysis. $\mathrm{K}$ was obtained following the method of Solé and Enrique (2001). Briefly, $100 \mathrm{mg}$ of sample were fused with $50 \%$ lithium metaborate $+50 \%$ lithium tetraborate. The fused pearl was measured with a Siemens 3000 XRF spectrometer calibrated against several international standards prepared in the same way. Results were accurate within $1 \%(1 \sigma)$ or better.

Argon was measured by isotope dilution $\left({ }^{38} \mathrm{Ar}\right.$ tracer $)$ with a VG1200B noble gas mass spectrometer operated under static vacuum. About 4-6 mg of each sample were fused with a $\mathrm{CO}_{2}$ laser in a UHV chamber. After fusion, evolving gases were purified with a cold finger, and two SAES getters, one operated at $400^{\circ} \mathrm{C}$ and the other at room temperature. Eight series of measurements of each mass were made sequentially and extrapolated to gas introduction time. Signal was acquired with a secondary electron multiplier. Variation coefficients for ${ }^{40} \mathrm{Ar}$ and ${ }^{38} \mathrm{Ar}$ are generally below $0.1 \%$ for ${ }^{40} \mathrm{Ar}$ and below $0.5 \%$ for ${ }^{36} \mathrm{Ar}$. Calibration of spike was made with LP-6 biotite and B4M muscovite. All analyses were made at Instituto de Geología, UNAM. The constants recommended by Steiger and Jäger (1977) were used throughout. The new radiometric ages range from 122.9 to $136.3 \mathrm{Ma}$ which is in accordance with other determinations on the area considering analytical errors (Table 1, Fig. 2).

\section{Absolute Intensity Determination \\ 3.1 Sample selection}

Pre-selection of the suitable samples for Thellier paleointensity experiments was mainly based on the demagnetization of natural remanent magnetization, temperature dependence of initial magnetic susceptibility, hystersis experiments and reflected light microscopy observation. Additionally, we estimated the viscosity index according to procedures described in Prévot et al. (1983). Determination of the viscosity index (Thellier and Thellier, 1944) allows to estimate the capacity of a sample to acquire a viscous 
Table 1. Results of K-Ar experiments (see text for further details).

\begin{tabular}{cccccccc}
\hline Analysis & Sample & Fraction & Weight $(\mathrm{mg})$ & $\% \mathrm{~K}$ & ${ }^{40} \mathrm{Ar}^{*}(\mathrm{moles} / \mathrm{g})$ & $\%{ }^{40} \mathrm{Ar}^{*}$ & $\mathrm{Age}(\mathrm{Ma}) \pm 1 \sigma$ \\
\hline 1011 & DS 1 & WR & 6.685 & 2.70 & $5.95 \mathrm{E}-10$ & 97.4 & $122.9 \pm 1.3$ \\
1016 & DS 1 & WR magnetic & 4.935 & 2.71 & $6.65 \mathrm{E}-10$ & 96.5 & $136.3 \pm 1.5$ \\
1012 & DS 3 & WR & 6.198 & 2.64 & $6.21 \mathrm{E}-10$ & 98.2 & $130.7 \pm 1.4$ \\
1014 & DS 4 & WR & 4.393 & 2.90 & $6.80 \mathrm{E}-10$ & 96.9 & $130.4 \pm 1.4$ \\
1018 & DS 11 & WR & 6.585 & 1.88 & $4.34 \mathrm{E}-10$ & 96.5 & $128.5 \pm 1.5$ \\
\hline
\end{tabular}
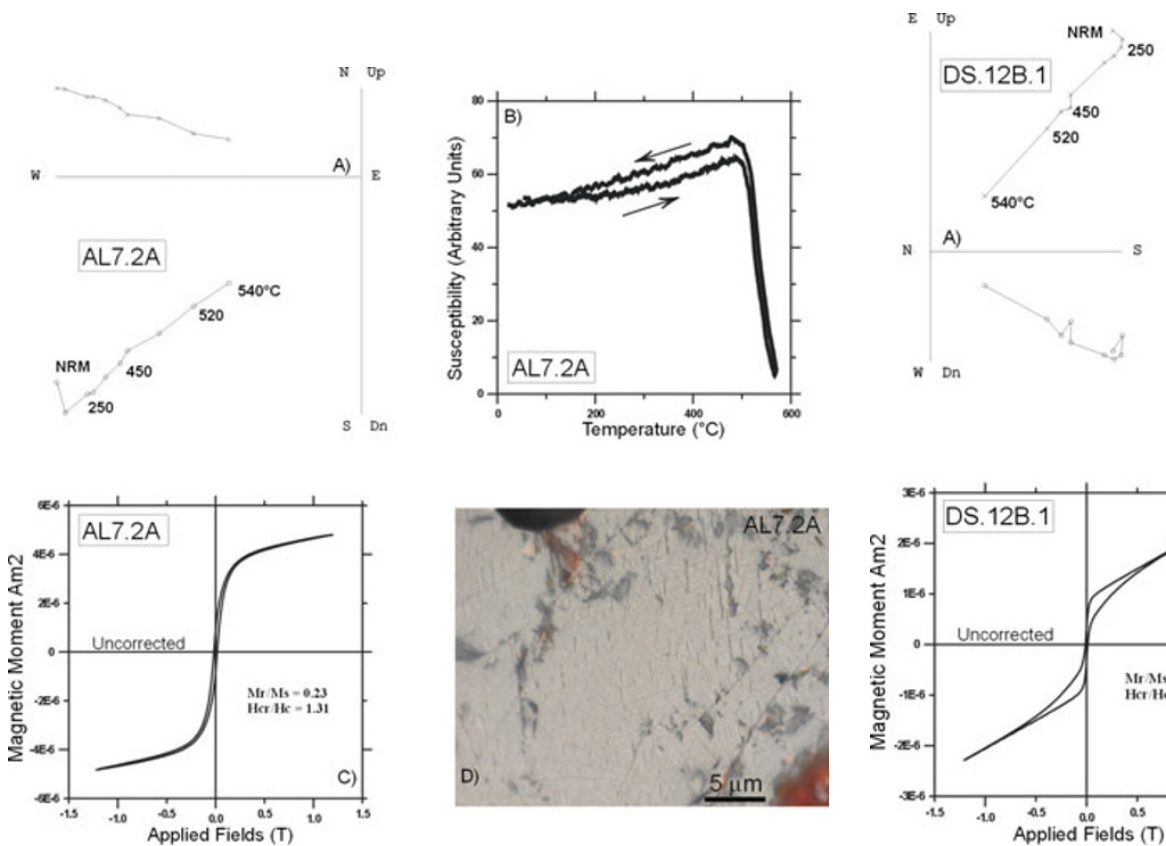
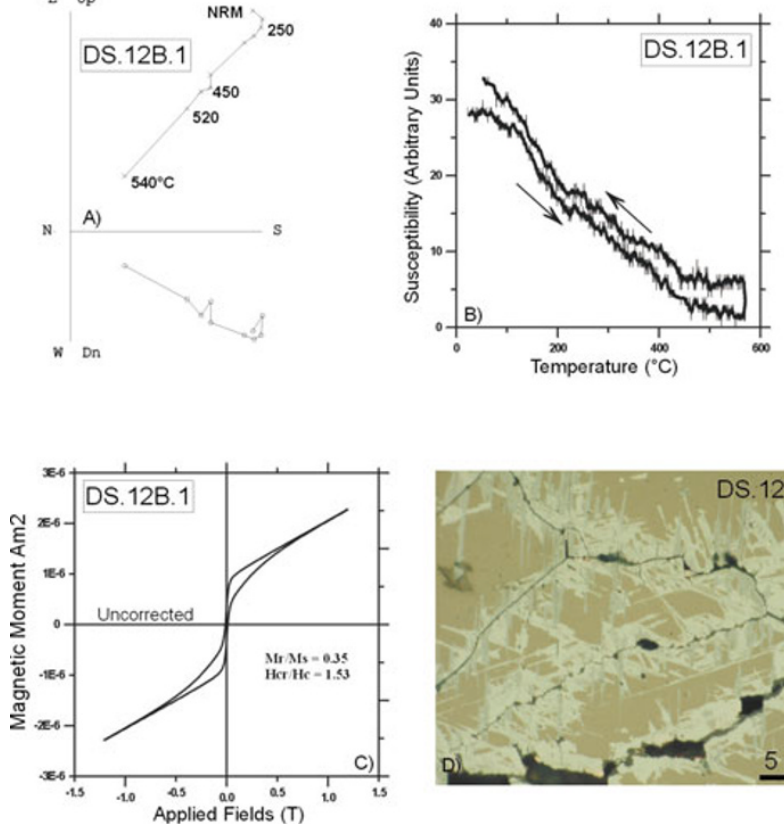

Fig. 3. Rock-magnetic properties of selected samples for paleointensity determination: a) Orthogonal vector plots of stepwise thermal demagnetization (stratigraphic coordinates). The numbers refer to temperatures in ${ }^{\circ} \mathrm{C}$. o-projections into the horizontal plane, $\mathrm{x}$-projections into the vertical plane. b) Susceptibility versus temperature curves. The arrows indicate the heating and cooling parts of the curves. c) Examples of hysteresis loops (uncorrected for dia and paramagnetism) of small chip samples and d) Reflected light microphotograph, oil immersion, crossed nicols.

remanent magnetization, and is therefore useful to obtain information about the sample's paleomagnetic stability. For this purpose, we placed the samples during 15 days with one of their axes aligned with Earth's magnetic field. After measuring their magnetization $\left(\mathbf{M}_{d}\right)$, they were placed for another 15 days in a field-free space, and the magnetization $\left(\mathrm{M}_{0}\right)$ was measured again. This allows to calculate the viscosity index $V=\left[\left(Z_{d}-Z_{0}\right): M_{n r m}\right] \times 100$, where $Z_{d}$ and $Z_{0}$ are respectively the magnetization components of $M_{d}$ and $M_{0}$ which are parallel to the magnetizing field. $\mathbf{M}_{n r m}$ is the intensity of natural remanent magnetization. All samples were subjected to these experiments and although viscosity indexes varied between 1.2 and $12.6 \%$, most values were lower than $5 \%$.

In total 88 samples belonging to 12 lava flows were preselected for the experiments. Most of samples (70 samples from 9 flows) comes from the Despeñaderos locality (Fig. 1). Selected samples show essentially two type of magnetic behaviors which can be described as follow:

3.1.1 Type 1 behavior (Fig. 3, right) One sample per flow, previousely demagnetized by alternating fields, was used to monitor susceptibility vs. temperature, hysteresis and microscopy observations.

Samples carry essentially a single and stable component of magnetization, observed upon thermal treatment (A). A generally minor secondary component, probably of viscous origin was present but was easily removed. The maximum angular deviations (MAD) are lower than $4^{\circ}$. Continuous susceptibility experiments (carried out in air) obtained on the same sample (B) yield Curie temperatures from 525 to $580^{\circ} \mathrm{C}$ compatible to almost pure magnetite. The cooling and heating curves are reasonably reversible and show evidence for single ferromagnetic phase. The hysteresis curves are quite symmetrical in all cases. Near the origin no potbellied or wasp-waisted behaviors (C) were detected (Tauxe et al., 1996), which probably reflects very restricted ranges of the opaque mineral coercivities. In the ratio plot of hysteresis parameters, samples fall in the pseudo-singledomain (PSD) grain size region (Day et al., 1977; Dunlop and Ozdemir, 2002). The observation of a thin polished section (D) show that the main magnetic mineral is Ti-poor titanomagnetite associated with ilmenite exsolution of trellis type.

3.1.2 Type 2 behavior (Fig. 3, left) These samples carry stable, uni-component remanence associated with minor, almost insignificant secondary component probably of viscous origin. (A). Continuous susceptibility plots are however quite noisy and it is hard to obtain correct pic- 
Table 2. Paleointensity results from Cordoba volcanic units, $n / N$ is the number of used/treated samples, $n$ is number of NRM-TRM points used for palaeointensity determination, Tmin-Tmax is the temperature interval used, $f, g$ and $q$ are the fraction of extrapolated NRM used, the gap factor and quality factor (Coe et al., 1978) respectively. $\gamma$ is the angle between the direction on characteristic remanent magnetization (ChRM) obtained during the demagnetization in zero field and that of composite magnetization (equal to NRM(T) if CRM(T) is zero (see text and Goguitchaichvili et al., 1999). $F_{E}$ is paleointensity estimate for individual specimen, and $\sigma\left(F_{E}\right)$ is its standard error; VDM and VDMe are individual and average virtual dipole moments. ${ }^{*} 400^{\circ} \mathrm{C}$ temperature step is missing for these samples.

\begin{tabular}{|c|c|c|c|c|c|c|c|c|c|c|c|c|}
\hline Site & Sample & Rock-mag & $n$ & $\begin{array}{c}\text { Tmin-Tmax } \\
\left({ }^{\circ}\right)\end{array}$ & $f$ & $g$ & $q$ & $\begin{array}{l}\gamma \\
\left({ }^{\circ}\right)\end{array}$ & $\begin{array}{c}F_{E} \pm \sigma\left(F_{E}\right) \\
\mu \mathrm{T}\end{array}$ & $\begin{array}{c}\text { VDM } \\
10^{22} \mathrm{Am}^{2}\end{array}$ & $\begin{array}{c}F_{E} \pm \text { s.d. } \\
\mu \mathrm{T}\end{array}$ & $\begin{array}{c}\text { VDMe } \\
10^{22} \mathrm{Am}^{2}\end{array}$ \\
\hline \multirow[t]{5}{*}{$\mathrm{AL}$} & AL7-3 & 1 & 8 & $300-560$ & 0.52 & 0.84 & 6.2 & 5.8 & $32.3 \pm 2.1$ & 6.55 & $29.0 \pm 2.4$ & $5.87 \pm 0.48$ \\
\hline & AL7-2B & 1 & 8 & $300-560$ & 0.66 & 0.81 & 12.6 & 1.3 & $30.3 \pm 0.7$ & 6.14 & & \\
\hline & AL8-1B & 1 & 7 & $300-540$ & 0.40 & 0.81 & 5.3 & 3.5 & $26.1 \pm 1.7$ & 5.29 & & \\
\hline & AL8-3C & 1 & $7^{*}$ & $250-540$ & 0.37 & 0.79 & 4.8 & 4.6 & $28.1 \pm 2.1$ & 5.70 & & \\
\hline & AL8-4C & 1 & 6 & $300-520$ & 0.39 & 0.83 & 6.5 & 3.9 & $28.0 \pm 2.7$ & 5.68 & & \\
\hline \multirow[t]{2}{*}{ DSP-2 } & DS7B & 1 & 8 & $250-540$ & 0.58 & 0.78 & 5.9 & 7.5 & $44.4 \pm 3.1$ & 8.61 & $42.3 \pm 3.0$ & $8.20 \pm 0.58$ \\
\hline & DS9A & 1 & 7 & $250-520$ & 0.38 & 0.77 & 5.5 & 6.3 & $40.2 \pm 2.6$ & 7.80 & & \\
\hline \multirow[t]{5}{*}{ DSP-3 } & DS11A & 2 & 8 & $250-540$ & 0.48 & 0.81 & 7.2 & 5.3 & $48.2 \pm 2.5$ & 9.03 & $42.8 \pm 4.3$ & $8.02 \pm 0.81$ \\
\hline & DS12B* & 2 & 7 & $250-520$ & 0.42 & 0.80 & 8.5 & 3.0 & $41.2 \pm 1.5$ & 7.72 & & \\
\hline & DS13B & 2 & 8 & $300-560$ & 0.62 & 0.76 & 5.6 & 2.3 & $37.4 \pm 2.2$ & 7.01 & & \\
\hline & DS14A & 2 & 8 & $250-540$ & 0.49 & 0.82 & 6.7 & 1.6 & $41.1 \pm 2.4$ & 7.70 & & \\
\hline & DS14B & 2 & 8 & $250-540$ & 0.43 & 0.79 & 7.9 & 2.2 & $46.0 \pm 2.1$ & 8.62 & & \\
\hline \multirow[t]{5}{*}{ DSP-4 } & DS19B & 1 & 7 & $300-540$ & 0.49 & 0.81 & 6.0 & 6.9 & $42.2 \pm 3.1$ & 7.90 & $46.1 \pm 2.5$ & $8.57 \pm 0.40$ \\
\hline & DS19C & 1 & 8 & $250-540$ & 0.52 & 0.80 & 5.9 & 4.6 & $45.1 \pm 3.2$ & 8.36 & & \\
\hline & DS20B & 1 & 6 & $350-540$ & 0.46 & 0.79 & 5.3 & 4.9 & $47.8 \pm 4.2$ & 8.86 & & \\
\hline & DS21A & 1 & 8 & $300-560$ & 0.84 & 0.80 & 25.8 & 2.6 & $47.4 \pm 1.2$ & 8.79 & & \\
\hline & DS21B & 1 & 7 & $350-560$ & 0.76 & 0.79 & 9.4 & 8.5 & $48.1 \pm 2.6$ & 8.92 & & \\
\hline \multirow[t]{3}{*}{ DSP-7 } & DS28B & 1 & 7 & $350-560$ & 0.72 & 0.80 & 14.2 & 2.9 & $35.1 \pm 1.3$ & 6.44 & $35.1 \pm 1.9$ & $6.43 \pm 3.58$ \\
\hline & DS29C & 1 & 7 & $350-560$ & 0.68 & 0.78 & 8.2 & 0.9 & $37.0 \pm 2.1$ & 6.79 & & \\
\hline & DS30C & 1 & 6 & $350-540$ & 0.56 & 0.79 & 8.6 & 3.5 & $33.1 \pm 1.6$ & 6.07 & & \\
\hline \multirow[t]{2}{*}{ DSP-8 } & DS33A & 1 & 6 & $350-540$ & 0.47 & 0.81 & 5.2 & 4.7 & $47.9 \pm 4.2$ & 8.41 & $53.0 \pm 7.2$ & $9.30 \pm 1.27$ \\
\hline & DS33B & 1 & 7 & $300-540$ & 0.44 & 0.82 & 4.8 & 4.0 & $58.1 \pm 6.4$ & 10.2 & & \\
\hline \multirow[t]{3}{*}{ DSP-9 } & DS37A & 1 & 7 & $350-560$ & 0.74 & 0.80 & 17.9 & 9.2 & $24.3 \pm 0.9$ & 4.42 & $25.4 \pm 2.6$ & $4.61 \pm 0.47$ \\
\hline & DS38A* & 1 & 8 & $250-560$ & 0.82 & 0.83 & 22.1 & 5.6 & $28.3 \pm 0.9$ & 5.15 & & \\
\hline & DS38B & 1 & 7 & $300-540$ & 0.69 & 0.77 & 14.0 & 6.3 & $23.5 \pm 0.8$ & 4.27 & & \\
\hline
\end{tabular}

ture due to very low initial signal. It may be seen however that theses curves are characterized by large decrease (B) at low/moderate temperatures, possibly due to superparamagnetism. This hypothesis is reinforced by the fact that the hystereis curves show well-defined wasp-waisted (C) behavior (Tauxe et al., 1996) probably due to presence of mixture single-domain and superparamagnetic grains (Goguitchaichvili and Prévot, 2000). Further evidence of SD-SP grains comes from the squareness vs. coercitive force $(\mathrm{Hc})$ relationship (Tauxe et al., 2002) pointing to the uniaxial SD and SP mixture. Conventional microscopy observations are rather difficult because of small size of most magnetic grains (commonly less than $2 \mu \mathrm{m}$ ). Larger grains that may be observed directly have naturally no great contribution in remanent magnetization. We note however, that this later group presents systematically Ti-poor titanomagnetites associated with ilmenite (sandwich form) and titanohematite exsolutions (D) formed as a result of oxidation of original titanomagnetite (usually Ti-rich) during the initial flow cooling.

\section{Paleointensity Experiments}

Paleointensity experiments were performed using the Thellier method (Thellier and Thellier, 1959) in its modified form (Coe et al., 1978). All heatings were made in a vac- uum better than $10^{-3}$ mbar. The temperature settings were established from earlier studies of the unblocking temperature spectrum (Geuna and Vizan, 1998). Ten temperature steps (Fig. 4) were distributed between room temperature and $560^{\circ} \mathrm{C}$, and the laboratory field was set to $30 \mu \mathrm{T}$. Control heatings, commonly referred as pTRM checks, were performed four times throughout the whole experiment. All remanences were measured using a JR6 spinner magnetometer.

We accepted only determinations that satisfied all of the following requirements:

1. Obtained from at least 6 NRM-TRM points corresponding to a NRM fraction larger than about $1 / 3$ (Coe'e quality factor $f>0.33$ ).

2. Yielding quality factor $q$ (Coe et al., 1978) of about 5 or more. In only two cases (samples AL8-3C and DS33B), we accepted determinations with slightly lower $q$ factors because the intensity was found close to the site-mean value and $f$ was above 0.47 .

3. Positive pTRM checks-We define pTRM checks as positive if the repeat PTRM value agree with the first measurement within $15 \%$. Because the small (lowtemperature) pTRMs are hard to measure precisely on the background of the full NRM/TRM, we must allow some larger deviation of pTRM checks (within 20\%). 

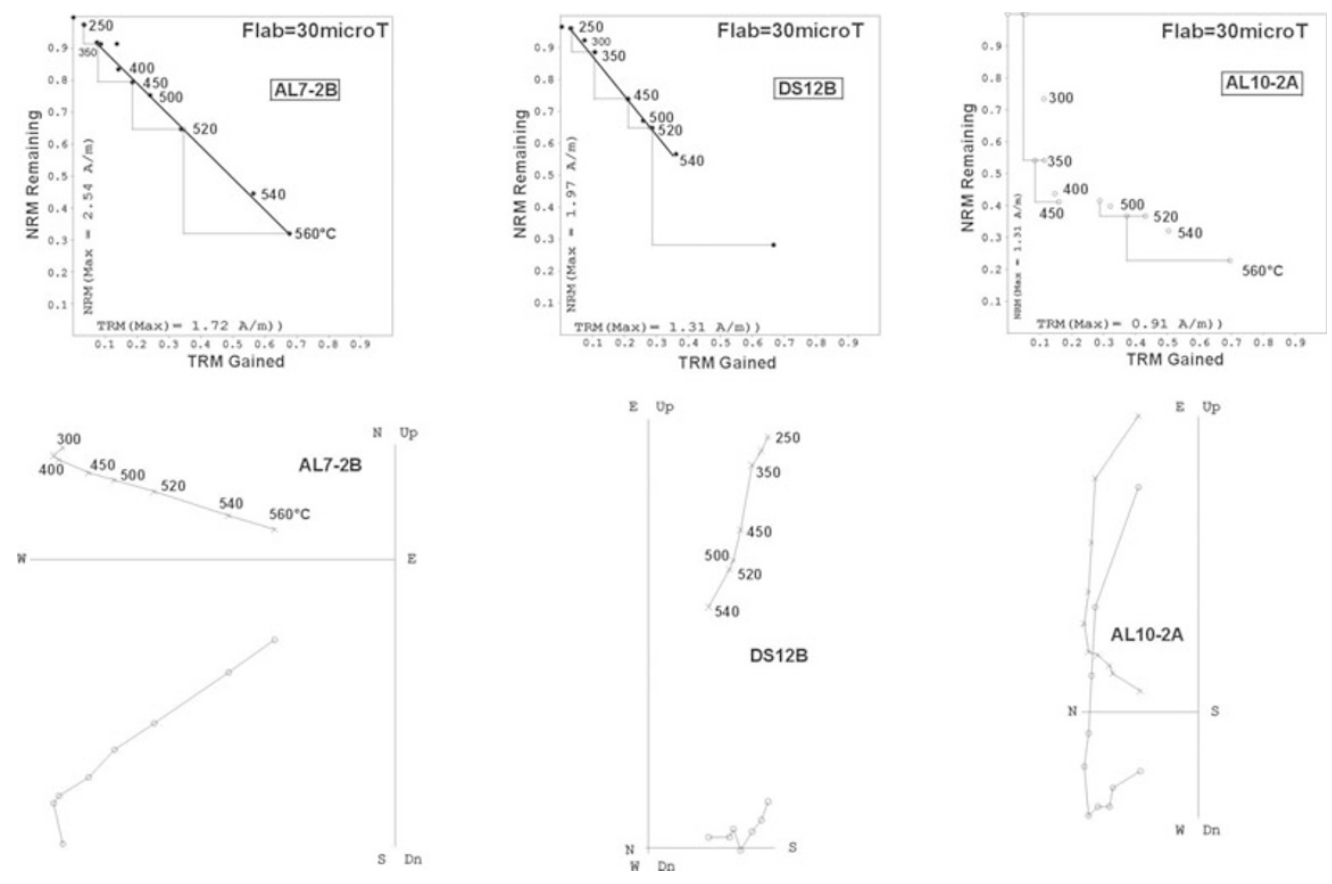

Fig. 4. The representative NRM-TRM plots and associated orthogonal diagrams for Cordoba samples. In the orthogonal diagrams we used same notations as in the Fig. 3.

4. The directions of NRM end points at each step obtained from paleointensity experiments are stable and linear pointing to the origin. No significant deviation of NRM remaining directions towards the direction of applied laboratory field was observed. To better illustrate this point, we calculated the ratio of potential CRM(T) to the magnitude of NRM(T) for each double heating step in the direction of the laboratory field during heating at T (Goguitchaichvili et al., 1999). Consequently, we now report the values of $\gamma$ [the angle between the direction on characteristic remanent magnetization (ChRM) obtained during the demagnetization in zero field and that of composite magnetization (equal to $\operatorname{NRM}(\mathrm{T})$ if $\mathrm{CRM}(\mathrm{T})$ is zero) obtained from the orthogonal plots derived from the Thellier paleointensity experiments] in Table 2 . For accepted determinations $\gamma$ values are all $<10^{\circ}$ which attest that no significant CRM was acquitted during the laboratory heatings. This approach is probably more restrictive than simple calculation of angle between the characteristic directions determined by Thellier experiments and by thermal demagnetization in zero field.

The main reason for failure of experiments was a typical 'concave-up' behaviour, observed for some samples (Fig. 4, sample AL10-2A), which may correspond to some irreversible variations of coercitive force (Dunlop and Özdemir, 1997) associated with large NRM lost without any correlated partial TRM acquisition during the subsequent cooling. As showed by Kosterov and Prévot (1998) this behavior is not only due to multidomain grains but also to some kind (not fully identified) transformation from a singledomain 'metastable' to multi-domain state which results in a large NRM lost without any correlated TRM acquisition during the subsequent cooling. This point is probably more complex puzzle in paleointensity and we have no explanation how these changes will lead to 'positive 'pTRM' checks.

Finally, 25 samples from 7 lava flows yielded apparently reliable absolute intensity determinations. We choose $560^{\circ} \mathrm{C}$ as a final step of Thellier paleointensity experiments due to the technical problems related to the paleointensity oven. We note however, that the data are of good technical qualities: The NRM fraction $f$ used for paleointensity determination ranges between 0.37 to 0.82 and the quality factor $q$ (Coe et al., 1978) varies from 4.8 to 25.8 , being normally greater than 5 (Table 2 ). These results correspond to data of good technical quality.

\section{Results and Discussion}

The correct identification of magnetic mineralogy is crucial for absolute paleointensity interpretation (Smirnov and Tarduno, 2005). The samples selected for Thellier paleointensity experiments should necessarily carry primary TRM (thermoremanent magnetization).

In present study, the selected samples present two types of magnetic properties. For the Type 1 samples (see text above and Fig. 3(a)) thermomagnetic investigations show that the remanence is carried in most cases by Ti-poor titanomagnetite, resulting of oxi-exsolution of original titanomagnetite during the initial flow cooling, which most probably indicates thermoremanent origin of a primary magnetization. Moreover, unblocking temperature spectra and relatively high coercivity point to 'small pseudo-single domain' magnetic structure grains as responsible for remanent magnetization. Single-component, linear demagnetization plots were observed in most cases.

The microscopy observation under reflected light on Type 2 samples shows Ti-poor titanomagnetites associated with 
Table 3. Selected VDMs and VADMs for the period 80 to $130 \mathrm{Ma}$. $N$ is the number of individual cooling units while $n$ is number of samples used for paleointensity determination. Abreviations are: SBG, submarine basaltic glass; Ti-rich TM, titanium rich titanomagnetite; Ti-poor TM, titanium poor titanomagnetite; PSD, pseudo single-domain; SP, superparamagnetic; SD, single domain; Hys, hysteresis loops; Js-T, saturation (induced) magnetization vs temperature curves; k-T, susceptibility vs temperature curves; IRM, isothermal remanent magnetization; SIRM(T), saturation isothermal remanent magnetization vs temperature; Obs., microscopy observation.

\begin{tabular}{|c|c|c|c|c|c|c|c|c|}
\hline Location & Age (Ma) & $N$ & $\begin{array}{l}10^{22} \mathrm{Am}^{2} \\
\end{array}$ & Rock & Mag. Carrier & Domain & Rock-Mag & Reference \\
\hline Inner Mongolia & $91.3 \pm 3.4$ & 144 & $2.8 \pm 1.6$ & Basalt & Ti-rich TM & PSD & Js-T, Hys & No Tanaka and Kono (2002) \\
\hline Inner Mongolia & 91.7 & 327 & $3.2 \pm 1.6$ & Basalt & Ti-rich TM & PSD & k-T, Hys & Yes Zhao et al. (2004) \\
\hline Troodos Ophiolite & 92 & 14739 & $8.1 \pm 4.3$ & SBG & Ti-poor TM & SP-SD & k-T, Hys & No Tauxe and Staudigel (2004) \\
\hline Arctic Canada & $95 \pm 1$ & 518 & $12.7 \pm 0.7$ & Plagioclase & Magnetite & PSD & Js-T, Hys & Yes Tarduno et al. (2002) \\
\hline Liaoing, NE China & $105.2-102.2$ & 2145 & $4.07 \pm 0.2$ & Basalt & Ti-rich TM & PSD & Js-T, Hys & Yes Zhu et al. (2004a) \\
\hline Rajmahal Traps & $114.5 \pm 1.5$ & 568 & $12.5 \pm 1.4$ & Plagioclase & Magnetite & PSD & Js-T, Hys & Yes Tarduno et al. (2001) \\
\hline Liaoing, NE China & $116.8 \pm 3.0$ & 125 & $4.2 \pm 0.1$ & Andesite & Ti-poor TM & PSD & Js-T, Hys & Yes Zhu et al. (2004c) \\
\hline Ontong Java Plateau & 120 & 1812 & $5.8 \pm 2.8$ & SBG & Ti-poor TM & PSD & SIRM(T), Hys & Yes Riisager et al. (2004) \\
\hline NE China & $125-120$ & 147 & $2.9 \pm 0.9$ & Basalt & Ti-poor TM & PSD & Js-T, Hys & No Pan et al. (2004) \\
\hline Liaoing, NE China & $122.7 \pm 0.6$ & 103 & $4.8 \pm 0.2$ & Andesite/Basalt & t Ti-poor TM & PSD & Js-T, Hys & No Zhu et al. (2004b) \\
\hline Cordoba, Argentina & $130-122$ & 257 & $7.3 \pm 1.7$ & Basalt & \multicolumn{4}{|c|}{ Ti-poor TM PSD, SP-SDk-T, Hys, IRM Yes This Study } \\
\hline Sihetun, NE China & $133-124$ & 2911 & $3.53 \pm 0.2$ & Basalt & Ti-poor TM & PSD & Js-T, Hys & No Zhu et al. (2003) \\
\hline
\end{tabular}

ilmenite (sandwich form) and titanohematite exsolutions (Fig. 3(d)) formed as a result of oxidation of original titanomagnetite (usually Ti-rich) during the initial flow cooling. This intergrowth develops typically beyond $600^{\circ} \mathrm{C}$ (Buddington and Lindsley, 1964; Haggerty, 1976, 1991, consequently, the NRM (natural remanent magnetization) carried by these samples should be a thermoremanent magnetization (TRM). Smirnov and Tarduno (2005) suggest however, that this process can occur at temperatures of $500^{\circ} \mathrm{C}$ or little bit below. In this case, paleointensity data may lead to the derivation of field values that are too low. They obtained values as low as 2.14 and $9.81 \mu \mathrm{T}$ studding some Early Proterozoic Matachewan dike swarm in Canada. We note however that in our case the paleointensity values obtained from Type 2 behaviour are quite high ranging from 37.4 to 48.2 $\mu \mathrm{T}$. The mean virtual dipole moment (VDM) value obtained from these samples is $8.02 \times 10^{22} \mathrm{Am}^{2}$ - compatible to the present geomagnetic field strength. Moreover, let us underline that the Type 1 is a dominant behavior (sites AL, DSP-2, DSP-4, DSP-7, DSP-8, DSP-9) against Type 2 (all samples of site DSP-3, Table 2) suspected to carry thermochemical remanent magnetization. Thus, even excluding these data from the analyses, the study mean VDM remains unchanged.

The site-mean paleointensity values obtained in this study range from $53.0 \pm 1.9$ to $25.4 \pm 2.6 \mu \mathrm{T}$ (Table 2) and the corresponding VDM's are ranging from $9.3 \pm 1.3$ to $4.6 \pm 0.5\left(10^{22} \mathrm{Am}^{2}\right)$. These data yield a mean value of $7.3 \pm 1.7 \times 10^{22} \mathrm{Am}^{2}$ which is basically similar to the present geomagnetic axial dipole $\left(7.8 \times 10^{22} \mathrm{Am}^{2}\right.$ after Barton et al., 1996).

Córdoba mean VDM is shown on Fig. 5 (see also Table 3) together with 11 other selected mean VDMs and VADMs (virtual axial dipole moment) for the period 130$80 \mathrm{Ma}$. We selected data using quite modest criteria (Riisager et al., 2004; Zhao et al., 2002) demanding a) the mean based on more than 9 successful determinations from at least three cooling units, b) no transitional data and c) paleointensity estimates obtained with Thellier (conventional or

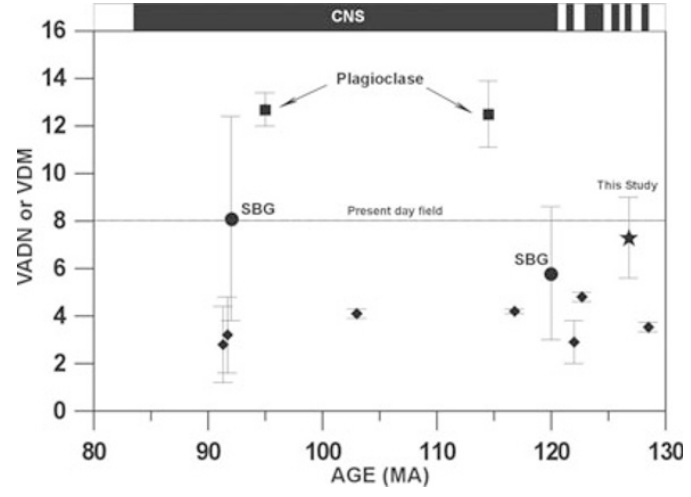

Fig. 5. Evolution of selected mean virtual dipole moments (VDMs) and virtual axial dipole moments (VADMs) for 80 to $130 \mathrm{Ma}$ (see also Table 3). Also shown is the geomagnetic polarity time scale to 130 Ma (Cande and Kent, 1995).

microwave) method with pTRM checks. Eight out of twelve data are obtained from subaerial lava flows, two are based on single plagioclase crystal paleointensity (Cottrel and Tarduno, 1999, 2000; Tarduno et al., 2001, 2002) while remained two VADMs are obtained using submarine basaltic glasses (SBG, see Tauxe and Staudidel, 2004 and Riisager et al., 2004). Our results are in agreement with SBG data but substantially lower with respect to plagioclase data. In contrast, the Córdoba mean VDM appears higher than those obtained from NE China (Tanaka and Kono, 2002; Zhao et al., 2002; Zhu et al., 2003; Zhu et al., 2004a, b, c; Pan et al., 2004).

Judjing from the large dispersion observed (Fig. 5), it is very difficult to make any firm conclusion about the longterm trend of geomagnetic paleointensity. Currently available paleointensity data for the time interval 130 to $80 \mathrm{Ma}$ suggest that geomagnetic field strength frequently fluctuated before and during the Cretaceous Normal Superchron while magnetic polarity maintained stable. This suggest that there is no simple relation between the strength of the Earth's magnetic field and reversal rates. An interesting 
finding is the similarity of Cordoba and Paraná (Goguitchaichvili et al., 2002) VDMs (133-132 Ma) which reinforces the hyphotesis about the unreliability of the 'Mesozoic Dipole Low’ first suggested by Prévot et al. (1990).

Acknowledgments. This study was supported by CONACYT (grants no. 42661).

\section{References}

Barton, C. E., R. Baldwin, D. Barraclough, S. Bushati, M. Chiappini, Y. Cohen, R. Coleman, G. Hulot, V. Kotze, V. Golovkov, A. Jackson, R. Langel, F. Lowes, D. McKnight, S. Macsmillan, L. Newitt, N. Peddie, J. Quinn, and T. Sabaka, International geomagnetic reference field, 1995 revision, Geophys. J. Int., 125, 318-321, 1996.

Buddington, A. F. and D. H. Linsley, Iron-titanium oxides minerals and synthetic equivalents, J. Petrol., 5, 310-357, 1964.

Cande, S. C. and D. V. Kent, Revised calibration of the geomagnetic polarity time scale for the Late Cretaceous and Cenozoic, J. Geophys. Res., 100, 6093-6095, 1995.

Coe, R., S. Grommé, and E. A. Mankinen, Geomagnetic paleointensities from radiocarbon-dated lava flows on Hawaii and the question of the Pacific nondipole low, J. Geophys. Res., 83, 1740-1756, 1978.

Cottrell, R. D. and J. A. Tarduno, Geomagnetic paleointensity derived from single plagioclase crystals, Earth Planet. Sci. Lett., 169(1-2), 1999.

Cottrell, R. D. and J. A. Tarduno, In search of high-fidelity geomagnetic paleointensities: A comparison of single plagioclase crystal and whole rock Thellier-Thellier analyses, J. Geophys. Res., 105, 23579-23584, 2000.

Day, R., M. Fuller, and V. A. Schmidt, Hysteresis properties of titanomagnetites: Grain-size and compositional dependence, Phys. Earth Planet. Int., 13, 260-267, 1977.

Dunlop, D. and Ö. Özdemir, Rock-Magnetism, Fundamentals and Frontiers, Cambrige University Press, 573 pp., 1997.

Dunlop, D. and Ö. Özdemir, Theory and application of the Day Plot, Theoretical curves and tests using titanomagnetite data, J. Geophys. Res., 107, doi: 1029/2001JB000486, 2002.

Geuna, S. E. and H. Vizán, New Early Cretaceous palaeomagnetic pole from Córdoba Province (Argentina): revision of previous studies and implications for the South American database, Geophys. J. Int., 135, 1085-1100, 1998.

Goguitchaichvili, A. and M. Prévot, Magnetism of oriented single crystals of hemo-ilmenite showing self-reversal of thermoremanent magnetization, J. Geophys. Res., 105, 2761-2781, 2000.

Goguitchaichvili, A., M. Prévot, J. Thompson, and N. Roberts, An attempt to determine the absolute geomagnetic field intensity in Southwestern Iceland during the Gauss-Matuyama reversal, Phys. Earth Planet. Int., 115, 53-66, 1999.

Goguitchaichvili, A., L. Alva-Valdivia, J. Urrutia-Fucugauchi, J. Morales, and O. Ferreira-Lopes, On the Reliability of Mesozoic Dipole Low: New Absolute Paleointensity Results from Parana Flood Basalts (Brazil), Geophys. Res. Lett., 29(13), 1655, 10.1029/2002GL015242, 2002.

Gordillo, C. E. and A. Lencinas, Geología y petrología del extremo norte de la Sierra de Los Cóndores, Córdoba, Bol. Academia Nacional de Ciencias, Córdoba, 46, 73-108, 1967.

Haggerty, S. E., Oxidation of opaque mineral oxides in basalts, in Oxides Minerals, edited by D. Rumble, Mineral. Soc. Amer., Reviews in Mineralogy, vol. 3, 300 pp., 1976.

Haggerty, S. E., Oxide textures-A mini atlas, Rev. Mineral., 25, 12-219, 1991.

Hulot, G. and Y. Gallet, Do superchrons occur without any paleomagnetic warning?, Earth Planet. Sci. Lett., 210, 191-201, 2003.

Kosterov, A. and M. Prévot, Possible mechanism causing failure of Thellier paleointensity experiments in some basalts, Geophys. J. Int., 134, 554-572, 1998.

Larson, R. L. and P. Olson, Mantle plumes control magnetic reversal frequency, Earth Planet. Sci. Lett., 107, 437-447, 1991.

Linares, E. and R. Gonzalez, Catálogo de edades radiométricas de la República Argentina, 1957-1987, Publicaciones especiales de la Asoc. Geol. Argentina, Ser. B, Didáctica y Complementaria, 19, 628 pp. Buenos Aires., 1990.

McFadden, R. T. and R. T. Merrill, Fundamental transitions in the geodynamo as suggested by paleomagnetic data, Phys. Earth Planet. Int., 91, 253-260, 1995.
McFadden, R. T. and R. T. Merrill, Evolution of geomagnetic reversal rate since 160 Ma: Is the process continuous?, J. Geophys. Res., 105, 2844528460, 2000.

Pan, Y., M. Hill, R. Zhu, and J. Shaw, Further evidence for low intensity of the geomagnetic field during the early Cretaceous time: using the modified Shaw and microwave technique, Geophys. J. Int., 157, 553564, 2004.

Prévot, M., R. S. Mainkinen, S. Grommé, and A. Lecaille, High paleointensity of the geomagnetic field from thermomagnetic studies on rift valley pillow basalts from the middle Atlantic ridge, J. Geophys. Res., 88, 2316-2326, 1983.

Prévot, M., E. A. Mankinen, R. S. Coe, and S. Grommé, The Steens Mountain (Oregon) geomagnetic polarity transition 2. Field intensity variations and discussion of reversal models, J. Geophys. Res., 90, 1041710448, 1985.

Prévot, M., M. E. Derder, M. McWilliams, and J. Thompson, Intensity of the Earth's magnetic field: evidence for a Mesozoic dipole low, Earth Planet. Sci. Lett., 97, 129-139, 1990.

Riisager, P., J. Riisager, X. Zhao, and R. S. Coe, Cretaceous geomagnetic paleointensities: Thellier experiments on Pillow lavas and submarine basaltic glass from the Ontong Java Plateau, Geochem. Geoph. Geosys., 4/18, doi: 10.1029/2003GC000611, 2004.

Smirnov, A. V. and J. A. Tarduno, Thermochemical remanent magnetization in Precambrian rocks: Are we sure the geomagnetic field was weak?, J. Geophys. Res., 110, B06103, 2005.

Solé, J. and P. Enrique, X-ray fluorescence analysis for the determination of potassium in small quantities of silicate minerals for $\mathrm{K}-\mathrm{Ar}$ dating, Analytica Chimica Acta, 440, 199-205, 2001.

Steiger, R. H. and E. Jäger, Subcomission on geochronology: Convention on the use of decay constants in geo- and cosmochronology, Earth Planet. Sci. Lett., 36, 359-362, 1977.

Tanaka, H. and M. Kono, Paleointensities from a Cretaceous basalt platform in Inner Mongolia, northeastern China, Phys. Earth Planet. Int., 133, 147-157, 2002.

Tarduno, J. A., R. D. Cottrell, and A. V. Smirnov, High geomagnetic intensity during the Mid-Cretaceous from Thellier analyses of single plagioclase crystals, Science, 291, 1779-1783, 2001.

Tarduno, J. A., R. D. Cottrell, and A. V. Smirnov, The Cretaceous superchron geodynamo: observations near the tangent cylinder, PNAS, 99, 14020-14025, 2002.

Tauxe, L. and H. Staudigel, Strength of the geomagnetic field in the Cretaceous Normal Superchron: New data fron submarine basaltic glass of the Trodoos Ophiolite, Geochem. Geoph. Geosys., 5/22, doi:10.1029/ 2003GC000635, 2004.

Tauxe, L., T. A. T. Mullender, and T. Pick, Pot-bellies, wasp-waists and superparamagnetism in magnetic hysteresis, J. Geophys. Res., 95, 1233712350, 1996.

Tauxe, L., Bertram, H. Neal, and Ch. Severino, Physical intrepretation of hysteresis loops: Micromagnetic modeling of fine particle magnetite, Geochem. Geophys. Geosyst., 3(10), 1055, doi:10.1029/ 2001GC000241, 2002.

Thellier, E. and O.Thellier, Recherches géomagnetiques sur les coulees volcaniques d'Auverne, Ann. Geophys., 1, 37-52, 1944.

Thellier, E. and O. Thellier, Sur l'intensité du champ magnétique terrestre dans le passé historique et géologique, Ann. Géophysique, 15, 285-376, 1959.

Zhao, X., P. Riisager, J. Riisager, U. Draeger, R. S. Coe, and Z. Zheng, New Palaeointensity results from Cretaceous basalt of Inner Mongolia, China, Phys. Earth Planet. Int., 141, 131-140, 2004.

Zhu, R., K. Hoffman, Y. Pan, R. Shi, and L. Daming, Evidence for weak geomagnetic intensity prior to the Cretaceous normal subchron, Phys. Earth Planet. Int., 136, 187-199, 2003.

Zhu, R., L. Ching-Hua, R. Shi, G. Shi, Y. Pan, and J. Shao, Paleointensities determined from the middle Cretaceous basalt in Liaoning Province, northeastern China, Phys. Earth Planet. Int., 142, 49-59, 2004a.

Zhu, R., L. Ching-Hua, R. Shi, G. Shi, Y. Pan, G. Shi, and J. Shao, Is there a precursor to the Cretaceous normal subchron? New paleointensity and age determination from Liaoning province, northeastern China, Phys. Earth Planet. Int., 147, 117-126, 2004b.

Zhu, R., K. Hoffman, S. Nomade, P. Renne, R. Shi, G. Shi, Y. Pan, and G. Shi, Geomagnetic paleointensity and direct age determination of the ISEA (M0r?) chron, Earth Planet. Sci. Lett., 217, 285-295, 2004c.

R. C. Ruiz, A. Goguitchaichvili (e-mail: avto@geofisica.unam.mx), S. E. Geuna, L. M. Alva-Valdivia, J. Solé, and J. Morales 